\title{
Mechanical Behaviors of Natural Sand Soils and Modified Soils in Heavy-Haul Railway Embankment
}

\author{
Yingying Zhao, ${ }^{1,2,3}$ Yang Yang $\mathbb{D}^{1}{ }^{1}$ Xianzhang Ling, ${ }^{3}$ Guoyu $\mathrm{Li}^{2}{ }^{2}$ and Weiming Gong ${ }^{1}$ \\ ${ }^{1}$ Key Laboratory of Concrete and Prestressed Concrete Structures of Ministry of Education, Southeast University, \\ Nanjing 211189, China \\ ${ }^{2}$ State Key Laboratory of Frozen Soil Engineering, Northwest Institute of Eco-Environment and Resources, \\ Lanzhou 730000, China \\ ${ }^{3}$ School of Civil Engineering, Harbin Institute of Technology, Harbin 150090, China \\ Correspondence should be addressed to Yang Yang; yyangce@gmail.com
}

Received 9 May 2020; Revised 29 July 2020; Accepted 19 August 2020; Published 27 August 2020

Academic Editor: Qiang Tang

Copyright ( 2020 Yingying Zhao et al. This is an open access article distributed under the Creative Commons Attribution License, which permits unrestricted use, distribution, and reproduction in any medium, provided the original work is properly cited.

The addition of chemical or mechanical materials, such as fibers or stabilizers, is frequently utilized in geotechnical engineering to improve the mechanical properties of problematic soils. In this study, great efforts have been made to obtain insight into the mechanical properties of the natural, fiber, and chemical additive-stabilized soil in heavy-haul railway embankment. A series of triaxial compression tests are conducted on the stabilized samples of different preparation conditions, including water content, compaction degree, confining pressure, fiber content, fiber length, stabilizer content, and curing time. Results show that the shear strength of natural soils shows a distinct increase after adding fiber and chemical additive stabilization. The optimum fiber content and length for fiber stabilization are $0.2 \%$ and $12 \mathrm{~mm}$, respectively. The initial tangential modulus and failure stress of chemical stabilized samples increase with the increase of additive dosage or curing time. Meanwhile, a brittle characteristic is observed. In the process of determining the reinforcement methods in practical projects, several other considerations are included, such as equipment and time available, especially for stabilized soils. The fiber-reinforced soils and stabilized soils are efficient for increasing the shear strength and changing of the brittleness character of the heavy-haul railway embankment. The results of this study could provide a valuable reference for geotechnical engineers dealing with soil problems, especially for the heavy-haul railway embankment.

\section{Introduction}

In practical projects, the diseases of heavy-haul railway include settlement, bed deformation, and shoulder extrusion. The thesis is based on the Bazhun heavy-haul railway project, located in the north of China. Investigations were conducted to identify the dynamic deformation module of the embankment. However, the natural soils of the embankment failed the quality of heavy-haul railway embankment that induces the engineering problems.

The purpose of the treatments is to satisfy the quality and safety of the design life of the project. There are numerous means to achieve this purpose, including replacement filling, compaction pile, geosynthetic materials reinforcement, chemical reinforcement, and other methods. Replacement filling is commonly used in the treatment of subgrade soils, but it has a high cost with the limitation of replacement material and transportation fees. Compaction pile should be used in the site with saturated clay, which is not suitable for the sandy soils. In some projects, geotextiles are selected to improve soil mechanical properties due to their highstrength, economical, anticorrosion ability. The utilization of additions including mechanical and chemical methods or combination of these two is frequently used in engineering to improve the strength and the stability of natural soils. There are two different types of chemical stabilizers: grouting materials and powder materials. For the former one, it includes cement, clay, water glass, lignin, propylene, epoxy resin, and urinary resin. For the late one, it includes cement, quicklime, fly ash, gypsum powder, and many other relative 
materials. However, most of the chemical stabilizers could induce environmental problems to some extent and, thus, it is necessary to develop a new environment-friendly material to stabilize the natural soils.

Soil stabilization attracted considerable interest among the above methods. The utilization of additions including mechanical and chemical methods, or combination of these two, is frequently used in engineering to improve the strength and the stability of natural soils. Many practicing projects adopted this method, such as repairing failed slopes [1], Earth retaining structures [2], antiearthquake geostructures [3], railway embankment [4-6], airfield construction, and other geotechnical engineering applications. The previous literature indicates that both fiber reinforcement and stabilizer reinforcement improve the shear strength and ductility of soils. A large number of direct shear tests [7-9], triaxial compression tests [10-13], and field tests $[14,15]$ have demonstrated that the shear strength has a large increase with the fiber reinforcing considering different influence factors such as confining pressure, fiber content, fiber orientation, and fiber properties. Fibers interact with the soil particles when bearing forces through surface friction and interlocking. The function will help to transfer the stress from the soil to the fiber. Besides, the tensile strength of fibers is mobilized and imparted to the soils resulting in the decrease of strain and the improvement of soil engineering properties. Another method employed by projects frequently is stabilizer reinforcement, which can improve the soil strength and increase resistance to softening. There are many cementitious materials utilized to stabilize the soils such as cement, lime, fly ash, bitumen, or combination of these [16-23]. The variation of mechanical properties of stabilized soils is closely related to the presence of organic matters, sulphates, sulphides, and carbon dioxide. The compaction condition, moisture content, temperature pozzolanic, freeze-thaw, and dry-wet cycles are also essential influence factors to the strength of stabilized soils [24]. However, these stabilizers are not suitable for many projects for non-environment-friendly and brittleness character [25]. These previous studies indicate that both fibers and stabilizers can improve the shear strength and ductility of soils. The mechanical properties of the reinforced soils are influenced by the natural soils characters, fibers, and stabilizers properties.

In order to develop a suitable soil treatment for the unsuitable heavy-haul railway embankment, an environment-friendly new stabilizer was developed to reinforce the locally available soils. Forty-one conventional triaxial compression tests are carried out on the natural soils, fiberreinforced soils, and stabilized soils with a newly developed stabilizer, considering different water content, compaction degree, confining pressure, fiber content, fiber length, stabilizer content, and curing time. The principal object of these tests was to study the properties of the reinforced soil under different conditions. A second objective was to determine if there is optimal value, such as fiber content, fiber lengths, stabilizer content, and curing time for the tested natural soils. Thirdly, comparing the mechanical properties of the fiber-reinforced soils and stabilized soils helps engineers making reasonable decisions. The results obtained from this research provide a valuable reference for the design and reinforcement project of the heavy-haul railway embankment in northwest district in China, as well as the other districts owning similar natural soil in the world. Besides, it can provide useful parameter reference for quality control of reinforced soils.

\section{Materials and Test Procedures}

2.1. Materials. The soils utilized in the tests were collected from the third section of Bazhun heavy-haul railway, which is located in the north of China. The coefficient of uniformity $(\mathrm{Cu})$ and the coefficient of gradation $(\mathrm{Cc})$ are 3.5 and 2.24, respectively. The curve of particle grade of subgrade soil is shown in Figure 1. The soils collected from the site were dried, crushed, and sifted to satisfy the requirement of the Chinese code for soil test of railway engineering (TB 10102-2010, 2010). Based on the compaction test of subgrade soils, the optimum water content and the maximum dry density are $8.5 \%$ and $2.06 \mathrm{~g} / \mathrm{cm}^{3}$, respectively.

Two different approaches were adopted to modify the soils, including reinforcing with discrete randomly distributed fiber and chemical stabilization in order to achieve the desired engineering properties. Polypropylene fibers (MP-I, produced by Bonnyfibres in Shanghai) were selected as reinforcement stabilizers because of the acid, alkali, and salt resistance properties with excellent dispersibility and safety. The properties of the fibers are given in Table 1 .

The new proposed stabilizer was designed by Harbin Institute of Technology, which was a mixture of several natural mineral materials and inorganic substances. The component proportion ratio for the mixture is $14 \%$ of silicate, $36 \%$ of aluminate, $21 \%$ of tetracalcium aluminoferrite, $9 \%$ of sulfate, $3 \%$ of silicon dioxide, and $17 \%$ of sulphoaluminate. Besides, the colour of the mixed powder is white with a fineness over $200 \mu \mathrm{m}$, and it has the characters of being odorless, nontoxic, and soluble in water.

\subsection{Preparation of Samples}

2.2.1. Samples of Natural Soils. Complying with the water content requirement in test procedures, the specific samples are prepared, given a good stir, and preserved for 24 hours, ensuring the uniform moisture of the final samples. After the preserving time, the soils are capable of making test specimens.

2.2.2. Samples of Fiber-Reinforced Soils. It is crucial to ensure the dispersion uniformity randomness of fibers, which is a significant factor affecting the mechanical property of mixtures in case of twine, spillover, and segregation [26]. The mixture was stirred by hand as follows:

(i) Dry the soils.

(ii) The required components, including water, fibers, and dried soils, are weighted precisely. Note that the 


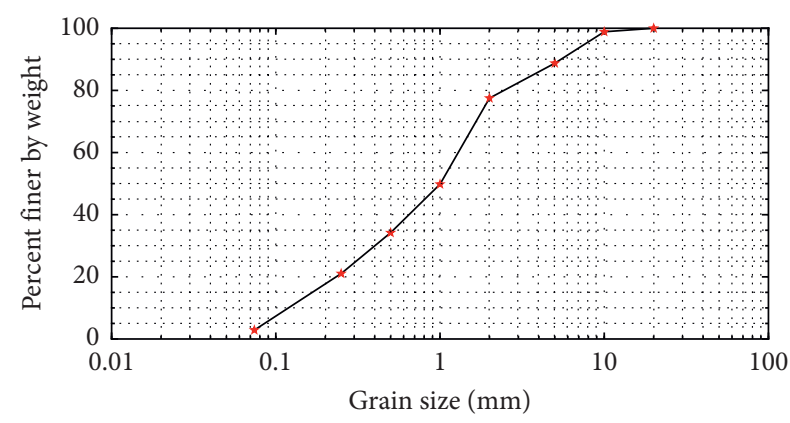

FIGURE 1: Curve of particle grade of subgrade soil.

water content is $2 \%$ more than the specific amount of water in the tests, aiming to avoid evaporation.

(iii) Divide all the materials into 5 parts.

(iv) The first part of the mixture must be moistened slightly by spray and keep stirring for 3 minutes.

(v) Repeat the fourth step until all the materials are added.

(vi) Cure the samples in the moist air cabinet for 24 hours.

2.2.3. Samples of Stabilized Soils. The specific amount of stabilizer, as planned, was mixed thoroughly with dry soils and water. In order to guarantee the uniformity of the mixture, the water was added by spray successively until the water content reaches $11.5 \%$, which is $3 \%$ more than the optimum moisture content. It was utilized in the chemical reaction process between minerals in soil with stabilizer. Then the prepared material is put into the air cabinet for curing. Finally, the test specimens are prepared with specific curing time.

2.3. Test Procedures. In this study, triaxial tests were conducted in the Cold and Arid Regions Environmental and Engineering Research Institute, Chinese Academy of Sciences, using MTS-810 on $61 \mathrm{~mm}$ in diameter and $125 \mathrm{~mm}$ high samples. All the materials were compacted in a triaxial test mold by a temping successive layer to ensure uniform compaction. The loading rate of straincontrolled undrained triaxial consolidation experiments was $1.25 \mathrm{~mm} / \mathrm{min}$. A serviceability failure criterion was defined as $15 \%$ axial strain for compressive loading if no evident peak value was detected in the tests. Otherwise, the peak value will be taken as the failure point. A complete list of tests is given as follows, considering different factors, to analyze the mechanics of natural soils, fiber-reinforced soils, and stabilized soils.

2.3.1. Test Procedures of Natural Soils. A variable-controlling approach was adopted to test the effect of water content, compaction degrees, and confining pressure levels. A summary of the tests is given in Table 2 .
2.3.2. Test Procedures of Fiber-Reinforced Soils. The effectiveness of the reinforcement is influenced by many factors, including fiber properties and soil properties. The effects of fiber content, fiber length, and confining pressure levels were taken into account, as shown in Table 3, with a water content of $8.5 \%$.

2.3.3. Test Procedures of Stabilized Soils. As for the stabilized soils, three factors were considered in the process of test design, which are stabilizer content, curing time, and confining pressure. Note that the stabilizer content is determined by the test output carried out by the Harbin Institute of Technology through the long-term trial-and-error approach. Based on the previous study, the best stabilizer content is about $5 \%$ to $7 \%$; that is the reason why the $5 \%$ content was determined to testify the effects of curing times and confining pressure levels. All the tests about stabilized soils with the same water content, $11.5 \%$, are listed in Table 4 .

\section{Typical Results and Discussion}

Conventional triaxial compression tests are conducted on natural soils, fiber-reinforced soils, and stabilized soils. Typical results of the tests provided material properties for analyses.

3.1. Natural Soils Test Results. As mentioned, natural soils were collected from the available local site. The study showed that the undrained stress-strain behavior of natural soils has a strain hardening character, so the failure criterion was defined as $15 \%$ axial strain. The effects of compaction degree, confining pressure level, and water content were analyzed in this study.

3.1.1. Compaction Degree Effect. Figures 2 and 3 illustrate, respectively, the deviatoric stress strain and the relationship between compaction degree and failure stress. The deviatoric stress increases with the axial strain with a turning point. After the point, the deviatoric stress increases slowly. Comparing the results of soils with different compaction degree, increasing the compaction degree generates an increase of the peak shear strength of the natural soils. The relationship between compaction degree and failure stress is almost linear, as shown in Figure 3. This linear relationship is generated because of the compaction degree, significantly affecting the void ratio. With the increase of the compaction degree, the natural soils become dense, and the addition of effective contact area between soil particles induces the improvement of interface friction.

3.1.2. Effect of Confining Pressure Level on the Strength Behavior of Natural Soils. Figure 4 presents the influence of confining pressure on the stress-strain behavior of natural soils under undrained conditions. With small strain, the deviatoric stress increases quickly. After about $2 \%$ of the strain, the increase becomes gentle. The results illustrate that, 
TABLE 1: The properties of fibers.

\begin{tabular}{lcccccc}
\hline $\begin{array}{l}\text { Density } \\
\left(\mathrm{g} / \mathrm{cm}^{3}\right)\end{array}$ & $\begin{array}{c}\text { Diameter } \\
(\mu \mathrm{m})\end{array}$ & $\begin{array}{c}\text { Melting point } \\
\left({ }^{\circ} \mathrm{C}\right)\end{array}$ & $\begin{array}{c}\text { Fire point } \\
\left({ }^{\circ} \mathrm{C}\right)\end{array}$ & $\begin{array}{c}\text { Elongation percentage after } \\
\text { fracture }\end{array}$ & $\begin{array}{c}\text { Modulus of elasticity } \\
(\mathrm{GPa})\end{array}$ & $\begin{array}{c}\text { Tensile strength } \\
(\mathrm{MPa})\end{array}$ \\
\hline 0.91 & 31 & $165 \sim 170$ & 590 & 30 & $\geq 3.5$ \\
\hline
\end{tabular}

TABLE 2: Test procedures of natural soils.

\begin{tabular}{lccc}
\hline Test & Water content (\%) & Degree of compaction (\%) & Confining pressure level (MPa) \\
\hline JSYS1 & 8.5 & 85 & 0.1 \\
JSYS2 & 8.5 & 90 & 0.1 \\
JSYS3 & 8.5 & 95 & 0.1 \\
JSYS4 & 8.5 & 98 & 0.1 \\
JSYS5 & 8.5 & 100 & 0.1 \\
JSW6 & 6.0 & 100 & 0.1 \\
JSW8 & 8.0 & 100 & 0.1 \\
JSW10 & 10.0 & 100 & 0.1 \\
JSW12 & 12.0 & 100 & 0.1 \\
JSW14 & 14.0 & 100 & 0.1 \\
JSWY1 & 8.5 & 100 & 0.1 \\
JSWY3 & 8.5 & 100 & 0.3 \\
JSWY5 & 8.5 & 100 & 0.5 \\
JSWY7 & 8.5 & 100 & 0.7 \\
JSWY9 & 8.5 & 100 & 0.9 \\
\hline
\end{tabular}

TABLE 3: Test procedures of fiber-reinforced soils.

\begin{tabular}{lccc}
\hline Test & Confining pressure level $(\mathrm{MPa})$ & Fiber length $(\mathrm{mm})$ & Fiber content $(\%)$ \\
\hline JXM1 & 0.1 & 0 & 0 \\
JXM2 & 0.1 & 12 & 0.1 \\
JXM3 & 0.1 & 12 & 0.2 \\
JXM4 & 0.1 & 12 & 0.3 \\
JXL1 & 0.1 & 0 & 0 \\
JXL2 & 0.1 & 3 & 0.2 \\
JXL3 & 0.1 & 9 & 0.2 \\
JXL4 & 0.1 & 12 & 0.2 \\
JXL5 & 0.1 & 18 & 0.2 \\
JXWY1 & 0.1 & 12 & 0.2 \\
JXWY2 & 0.3 & 12 & 0.2 \\
JXWY3 & 0.5 & 12 & 0.2 \\
JXWY4 & 0.7 & 12 & 0.2 \\
JGWY2 & 0.3 & 12 & 0.2 \\
\hline
\end{tabular}

TABLE 4: Test procedures of stabilized soils.

\begin{tabular}{lccc}
\hline Test & Confining pressure level (MPa) & Stabilizer content (\%) & Curing time (day) \\
\hline JGN0 & 0.1 & 0 & 3 \\
JGN3 & 0.1 & 3 & 3 \\
JGN5 & 0.1 & 5 & 3 \\
JGYH3 & 0.1 & 5 & 3 \\
JGYH14 & 0.1 & 5 & 14 \\
JGYH28 & 0.1 & 5 & 28 \\
JGWY1 & 0.1 & 5 & 3 \\
JGWY2 & 0.3 & 5 & 3 \\
JGWY3 & 0.5 & 5 & 3 \\
JGWY4 & 0.7 & 5 & 28 \\
JGWY5 & 0.1 & 5 & 28 \\
JGWY6 & 0.3 & 5 & \\
\hline
\end{tabular}




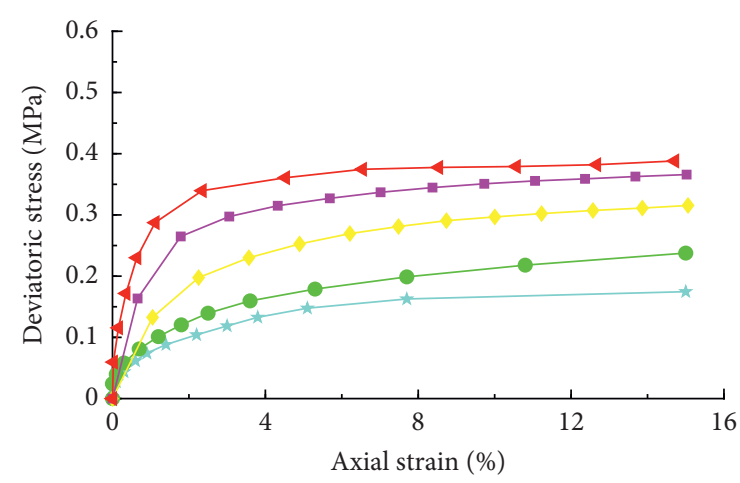

Compaction degree

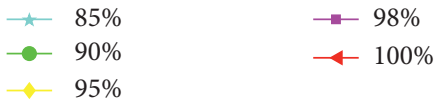

FIGURE 2: Effect of compaction degree on performance of natural soil (confining pressure $=0.1 \mathrm{MPa}$; water content $=8.5 \%$ ).

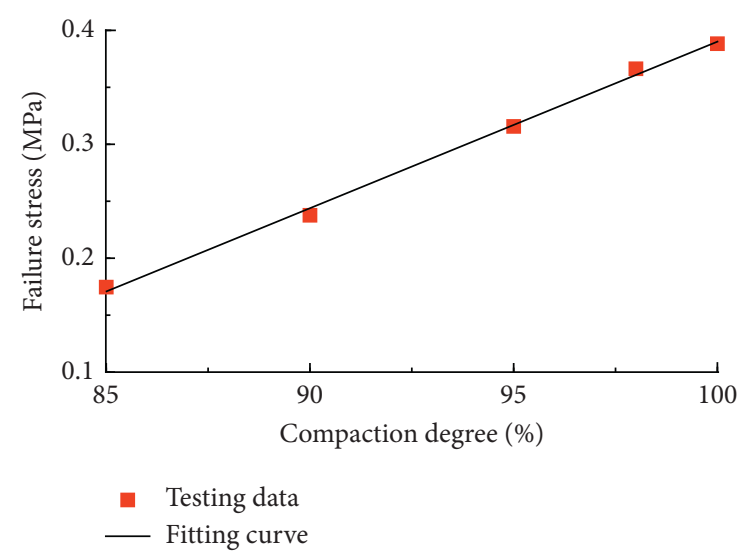

FIgURE 3: The relationship between compaction degree and failure stress (confining pressure $=0.1 \mathrm{MPa}$; water content $=8.5 \%$ ).

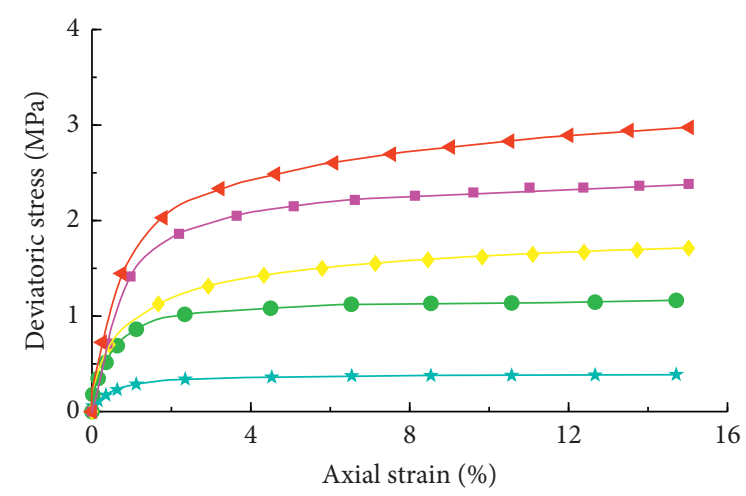

Confining pressure (MPa)

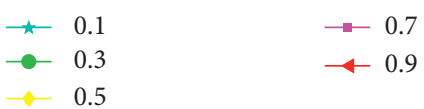

FIGURE 4: Influence of confining pressure on the stress-strain behavior of natural soils (compaction degree $=100$; water content $=8.5 \%$ ). with the increment of the confining pressure, the shear strength of natural soils improved gradually. The improvement in the fail stress under different confining pressure is shown in Figure 5. The cohesion intercept and friction angle for natural soils are $0 \mathrm{MPa}$ and $38^{\circ}$, respectively. Under confining pressure, the horizontal dilatancy was restrained, which induces the soil particles harder to slide and roll. Hence, the soil strength is improved significantly.

3.1.3. Effect of Water Content on the Strength Behavior of Natural Soils. Typical results of natural soils with different water contents are presented in Figure 6. The water content heavily influences the deviatoric response of the natural soils. Figure 7 illustrates that if the water content is lower than the optimum water content, failure stress will increase with the increase of water content. However, it will decrease if the water content is increased over the optimum value. For the soils containing more than $10 \%$ water, the shear strength decreased quickly. With a low water content, the failure stress is inferior to the value of optimum water content for the disintegration of the soil particles bonding. Water content higher than the optimum value also induces the weakening of soil shear strength by the deceleration of absorption forces and friction interaction of soil particles.

3.2. Test Results of Fiber-Reinforced Soils. The contribution of random discrete fibers on the strength of reinforced soil is remarkable. Randomly oriented fibers incorporating soil particles generated surface friction bond and interlocking effect. This function allows the stress transfer from soil to fibers, which will reduce the strains in reinforced soil, resulting in the improvement of soil strength. The principal object of this fiber-reinforced soil test was to study the properties of the fiber-reinforced soil with different fiber content, length, and confining pressure. A second objective was to determine if there are optimal fiber content and fiber lengths for the tested natural soils.

3.2.1. Effect of Fiber Content on the Strength Behavior of Fiber-Reinforced Soils. Typical results of fiber-reinforced soil with different fiber contents are presented in Figure 8. The results recorded are in line with the already published results by Heineck et al. [27]. The presence of fibers has little influence on the deviatoric stress under small strain $(0.01 \%$ $0.3 \%)$. As the strain developed, the effect of fiber content on the shear strength becomes apparent, especially under considerable strain $(0.3 \% \sim 15 \%)$, for the surface friction bond and interlocking function contributing to the soil pressure. The failure deviatoric strength envelopes for fiberreinforced soils are shown in Figure 9, based on a serviceability failure criterion and $15 \%$ axial strain for compress loading. The fiber content heavily influences the deviatoric response of the reinforced soil and the influence has a limitation. The optimal fiber content is $0.2 \%$ for the tested soils. If the percentage of fiber is lower than it, the soils have other new voids leading to the low shear strength. 


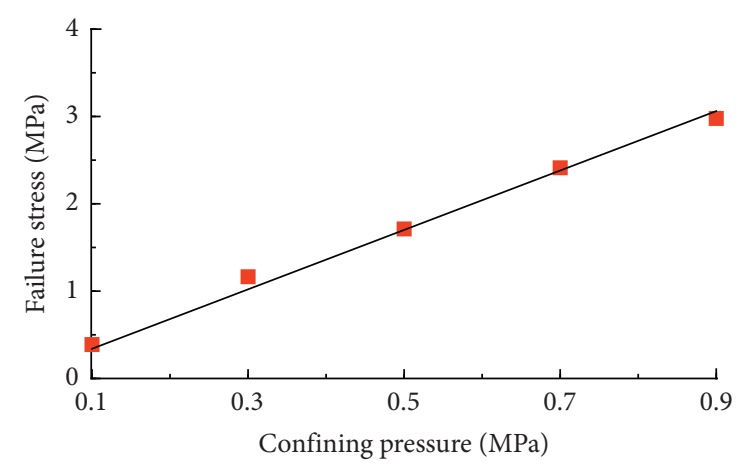

- Testing data - Fitting curve

Figure 5: The relationship between confining pressure and failure stress $($ compaction degree $=100$; water content $=8.5 \%$ ).
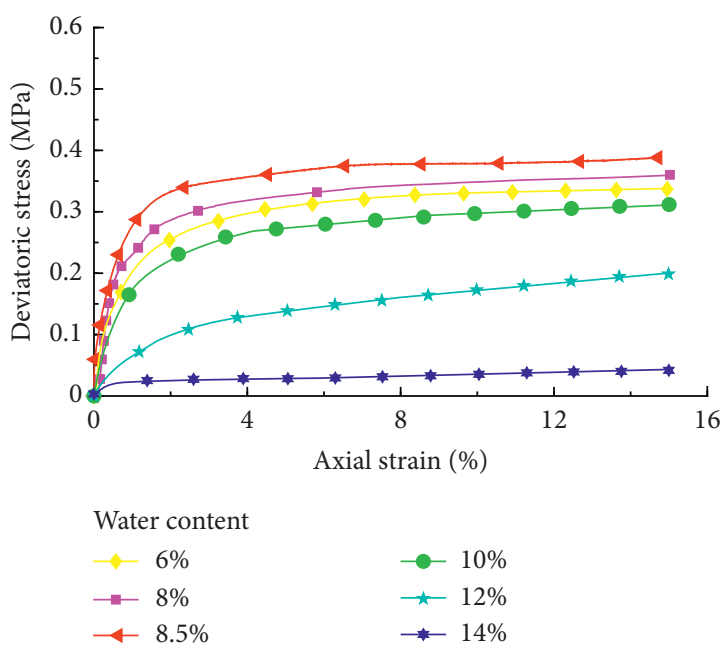

Figure 6: Deviatoric stress-axial strain behavior for natural soil with different water contents (confining pressure $=0.1 \mathrm{MPa}$; compaction degree $=100$ ).

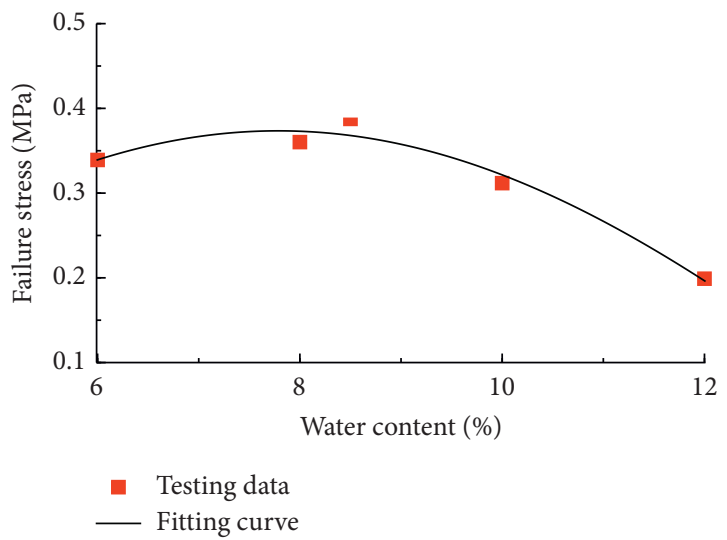

FIGURE 7: The relationship between water content and failure stress (confining pressure $=0.1 \mathrm{MPa}$; compaction degree $=100$ ).
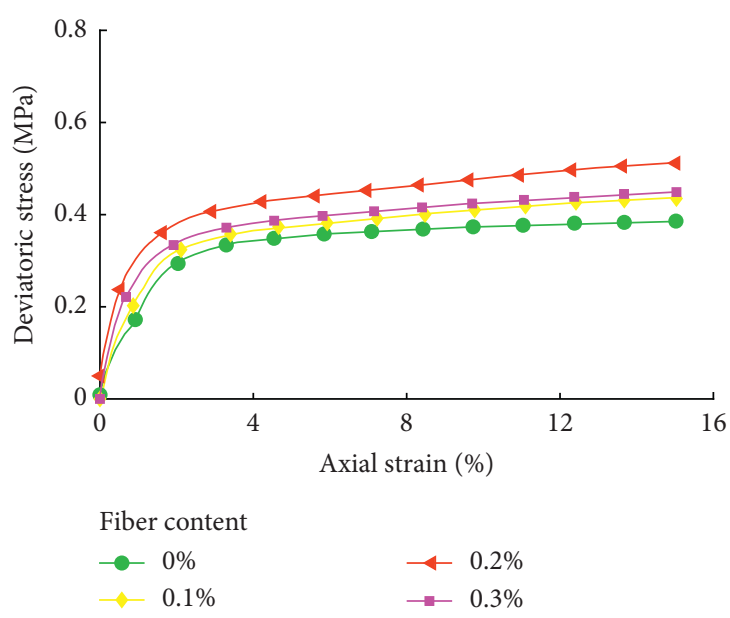

FIGURE 8: Deviatoric stress-axial strain for fiber-reinforced soil with different fiber contents (confining pressure $=0.1 \mathrm{MPa}$; compaction degree $=100)$.

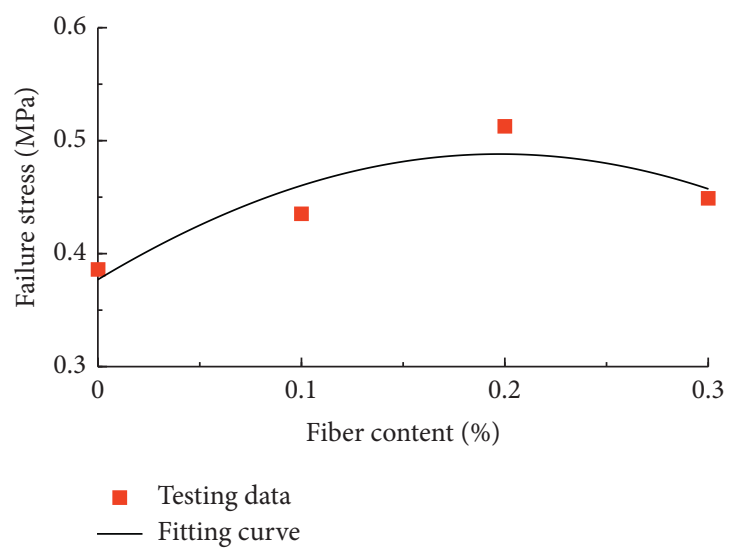

FIGURE 9: Deviatoric strength envelopes for fiber-reinforced soil with different fiber contents (confining pressure $=0.1 \mathrm{MPa}$; compaction degree $=100$ ).

Moreover, with the increment of the fiber content, the dense degree of the reinforced soil increases gradually until the optimal point. However, the dense degree will decrease after the optimal point for the density of fiber is lower than the soil. Besides, the increment of fiber weakens the interlocking function.

3.2.2. Effect of Fiber Length on the Strength Behavior of FiberReinforced Soils. Soils were reinforced with various length fibers, but the same material properties were utilized to study the influence of fiber length on the modification of shear strength at confining stress of $0.1 \mathrm{MPa}$ and fiber content of $0.2 \%$. The deviatoric stress-axial strain for fiber-reinforced soil with different fiber length is illustrated in Figure 10. It was found that the longer the fiber, the more significant deviatoric stress of the soil. But the deviatoric stress decreases when the fiber length is 


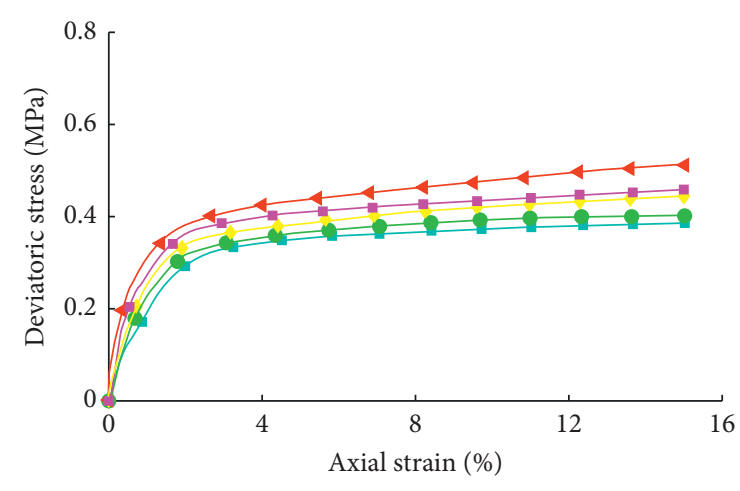

Fiber length (mm)

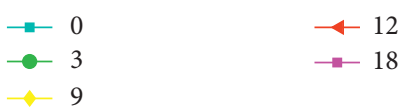

Figure 10: Deviatoric stress-axial strain of fiber-reinforced soil with different fiber length (confining pressure $=0.1 \mathrm{MPa}$; compaction degree $=100$; fiber content $=0.2 \%$ ).

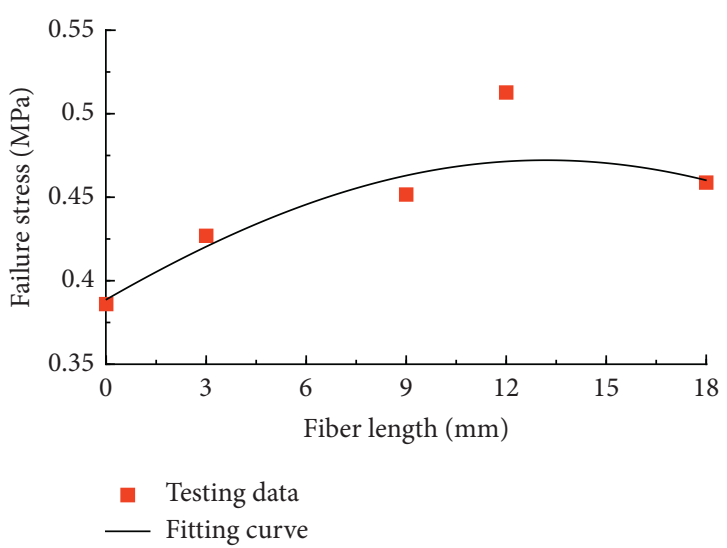

FIGURE 11: Deviatoric strength envelopes for fiber-reinforced soil with different fiber length (confining pressure $=0.1 \mathrm{MPa}$; compaction degree $=100$; fiber content $=0.2 \%$ ).

$18 \mathrm{~mm}$, over the optimal length, which is considered as $12 \mathrm{~mm}$, as shown in Figure 11. This result was most probably due to the change in mechanical interaction influence. The tensile force generated in the fiber can endure the interfacial shear stress of soils and it was proportionate to the fiber length. However, for soils with short fiber, there is not enough tensile force and the surface friction bond is weak, which had little influence on the improvement of the soil strength.

\subsubsection{Effect of Confining Pressure Level on the Strength} Behavior of Fiber-Reinforced Soils. Four different confining pressures were adopted at optimal length and optimal fiber content to identify the influence of confining pressure on the shear strength of fiber-reinforced soil. The recorded results are presented in Figure 12. The deviatoric strength increased along with the increase of confining pressure, for higher confining pressure can

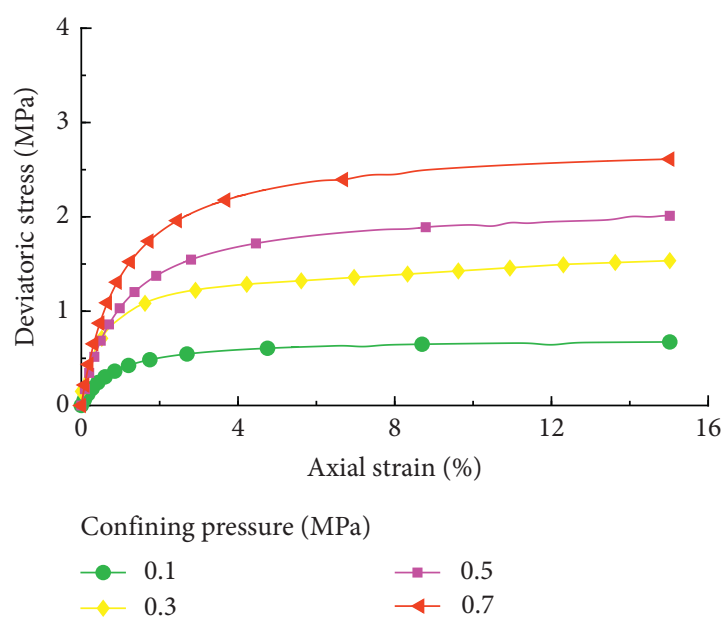

Figure 12: Deviatoric stress-axial strain of fiber-reinforced soil with different confining pressure (fiber length $=12 \mathrm{~mm}$; compaction degree $=100$; fiber content $=0.2 \%$ ).

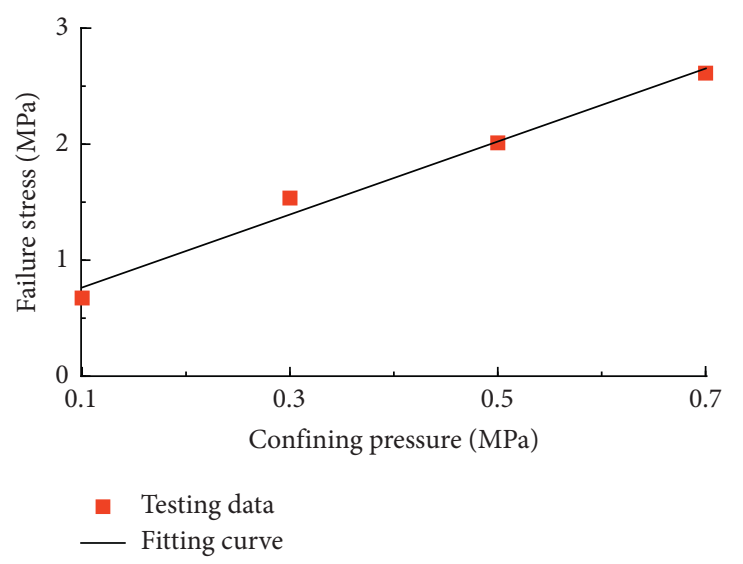

FIGURE 13: Deviatoric strength envelopes for fiber-reinforced soil with different confining pressure (fiber length $=12 \mathrm{~mm}$; compaction degree $=100$; fiber content $=0.2 \%$ ).

enhance the interaction forces between fibers and soil particles. The failure deviatoric strength envelopes for the fiber-reinforced soils with different confining pressure are almost linear as shown in Figure 13. The cohesion intercept and friction angle for fiber-reinforced soil are $0.11 \mathrm{MPa}$ and $37.7^{\circ}$, respectively. Also, the comparison between natural soils and fiber-reinforced soils can be generated from Figures 4 and 8 . The latter has a significant improvement in the cohesion intercept but less change on the friction angle.

3.3. Test Results of Stabilized Soils. Conventional triaxial compression tests are conducted on stabilized soils made of stabilizer and natural soils. The reported experimental study includes various stabilizer contents, curing time, and confining pressure to evaluate the feasibility of using this new stabilizer in the reinforcement of natural soils in heavy-haul railway embankment. 


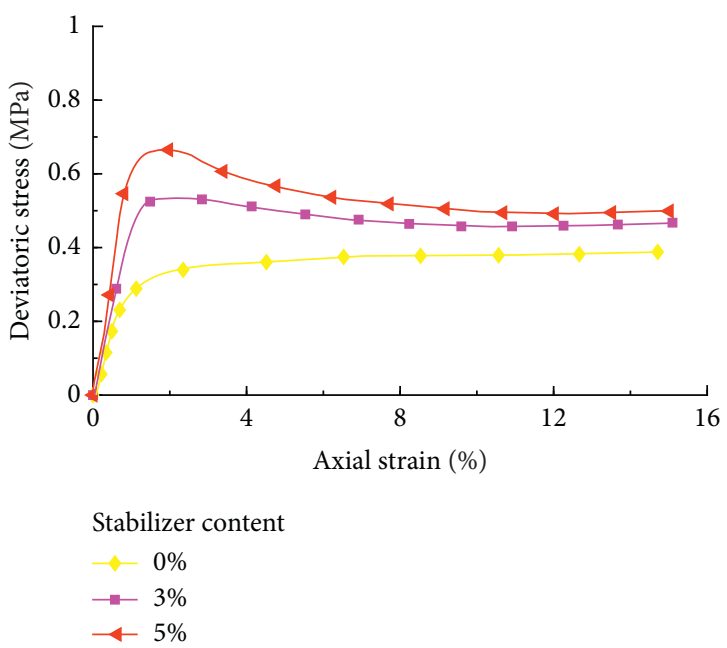

FIGURE 14: Influence of stabilizer content on deviatoric stress-axial strain relationship (confining pressure $=0.1 \mathrm{MPa}$; curing time $=3$ days).

\subsubsection{Effect of Stabilizer Content on the Strength Behavior of} Stabilized Soils. As shown in Figure 14, the deviatoric stressaxial strain relationship under confining pressure of $0.1 \mathrm{MPa}$ and curing time of 3 days illustrates that the stabilization effect results in a prepeak restrain of the dilatancy. After the peak shear strength, the disintegration of the bonding leads the stabilized soils to undergo plastic flow, which is the different fundamental behavior between stabilized soils and natural soils. The initial stiffness, peak shear strength, and residual shearing resistance are improved because of the utilization of stabilizer. The peak deviatoric stress of stabilized soils with $5 \%$ of stabilizer is $0.67 \mathrm{MPa}$, which is 1.8 times higher than that of the natural soils. However, the postpeak stress decrease speed increase with the increase of the stabilizer content, which means that the increase of the stabilizer induced an increase in brittleness. Figure 15 illustrates the failure stress of the stabilized soils with different stabilizer content. Increasing the stabilizer content generates an increase of the failure stress. This character is because of the internal confinement or cohesion improvement when more stabilizer content is added in the soils. The internal bonding is destroyed in the extensive strain process when the shear strength is similar to natural soils.

\subsubsection{Effect of Curing Time on the Strength Behavior of} Stabilized Soils. Figure 16 presents the deviatoric stress-axial strain relationship for stabilized soils with different curing times. These results illustrate the effect of curing time on the shear strength of stabilized soils. The peak shear strength increases with the increase of curing time for stabilized soils, for the stabilizer undergoing a chemical reaction to a great extent when curing time is extended, as shown in Figure 17. However, the deterioration of the internal bonding generated a rapid postpeak strain softening. It is also interesting to indicate that, with the increase of the strain, the deviatoric stress tends to be gentle until the end of the tests. The comparison illustrates that, with the increase of curing time, the brittleness was aggravated.

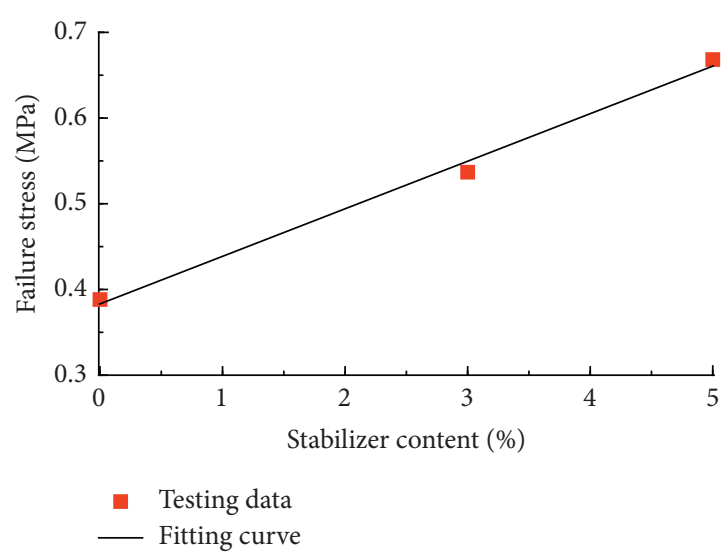

FIGURE 15: Deviatoric strength envelopes for stabilized soils with different stabilizer content (confining pressure $=0.1 \mathrm{MPa}$; curing time $=3$ days)

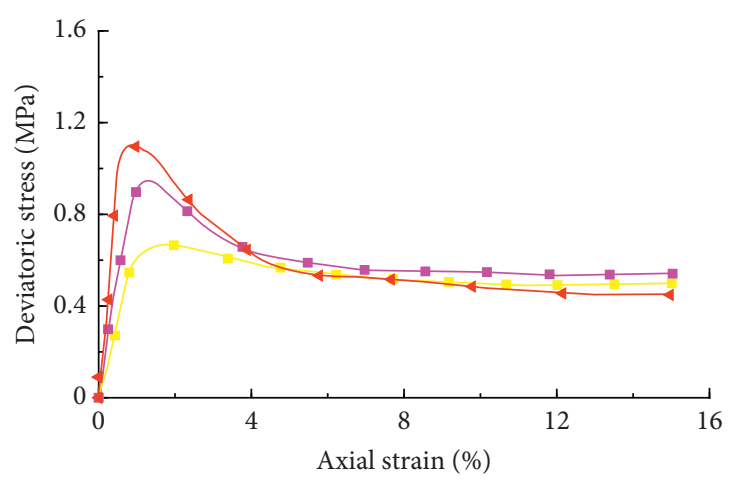

$$
\begin{aligned}
& \text { Curing time (day) } \\
& -3 \\
& -\quad 14 \\
& -\quad 28
\end{aligned}
$$

FIGURE 16: Deviatoric stress-axial strain relationship for stabilized soils with different curing times (confining pressure $=0.1 \mathrm{MPa}$; stabilizer content $=5 \%$ ).

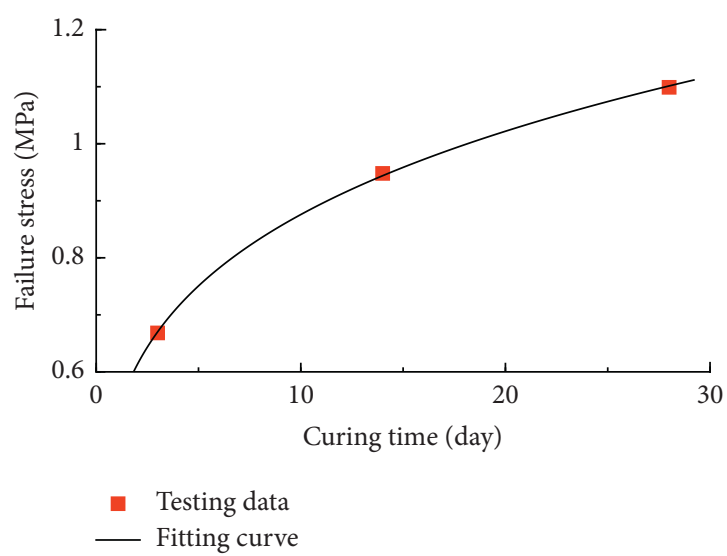

FIgURE 17: The failure stress for stabilized soils with different curing times (confining pressure $=0.1 \mathrm{MPa}$; stabilizer content $=5 \%)$. 


\subsubsection{Effect of Confining Pressure Level on the Strength} Behavior of Stabilized Soils. The response of stabilized soils with $5 \%$ of stabilizer content and 3 days of curing time to axial compressive stress under different confining pressure is illustrated in Figure 18. The results showed that, with the increase of confining pressure, the failure stress and residual shearing resistance are improved significantly. For instance, the failure stresses for the samples under $0.1 \mathrm{MPa}$ and $0.3 \mathrm{MPa}$ are $0.67 \mathrm{MPa}$ and $1.26 \mathrm{MPa}$, respectively, with $88 \%$ increase. Besides, the residual shearing resistances for them are $0.41 \mathrm{MPa}$ and $0.84 \mathrm{MPa}$, with a double increase. Figure 19 shows the result of deviatoric strength envelopes for stabilized soils, which presented the almost linear relationship between confining pressure and failure stress. Confining pressure protected the samples from horizontal dilatation, in which way the cracks inside the stabilized soils are restrained and the shear strength of the soils increased. The cohesion intercept and friction angle obtained from the test results are $0.11 \mathrm{MPa}$ and $34.7^{\circ}$, respectively.

\subsection{Comparison}

3.4.1. Deviatoric Stress-Axial Strain Relations. For better understanding the characteristic of different kinds of soils, clear pictures of the behavior natural soils, fiber-reinforced soils, and stabilized soils under the confining pressure of $0.1 \mathrm{MPa}$ are shown in Figure 20. Fiber-reinforced soils in Figure 20 have a fiber content of $0.2 \%$ and stabilized soils have a stabilizer content of 5\%. Evaluation of the comparison of the shear strength of these soils suggests that fiberreinforced soils and stabilized soils are significantly improved. For natural soils, there is no peak stress point in the relationship of deviatoric stress-axial strain, which is similar to the character of fiber-reinforced soils. The behavior of stabilized soil is different from those of the other two soils, showing a prepeak restrain of the dilatancy and brittleness character. The initial tangential moduli of stabilized soil, natural soil, and fiber-reinforced soil are $134.3 \mathrm{MPa}$, 93.9 $\mathrm{MPa}$, and 85.4 $\mathrm{MPa}$, respectively. The initial tangential modulus of stabilized soil is higher than those of natural soil and fiber-reinforced soil. Stabilized soils obtained the peak shear strength at $2 \%$ axial strain; then the deviatoric stress decreased. Compared with stabilized soils, the other soils' deviatoric stress increased with the growing up of strain until the failure strain.

The cohesion intercept and friction angle obtained from the test results of different confining pressure are given in Table 5. Note that the fiber-reinforced soils in Table 5 have a fiber content of $0.2 \%$ and the stabilized soils have a stabilizer content of $5 \%$. The cohesion intercepts for fiber-reinforced soils and stabilized soils are increased to $0.11 \mathrm{MPa}$; at the same time, the friction angle generated a decrease.

3.4.2. Failure Stress. Figure 21 presents the failure stress for different soils at confining pressure of $0.1 \mathrm{MPa}$. The fiberreinforced soils in Figure 21 from left to right have fiber content of $0.1 \%, 0.2 \%$, and $0.3 \%$, respectively. The left and the right stabilized soils columns shown in Figure 21 have a

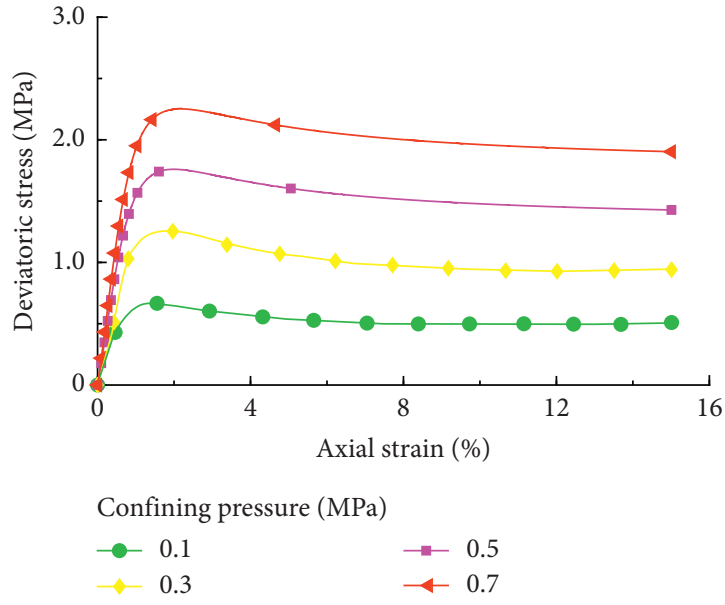

FIGURE 18: Deviatoric stress-axial strain relationships for stabilized soils with different confining pressure (stabilizer content $=5 \%$; curing time $=3$ days).

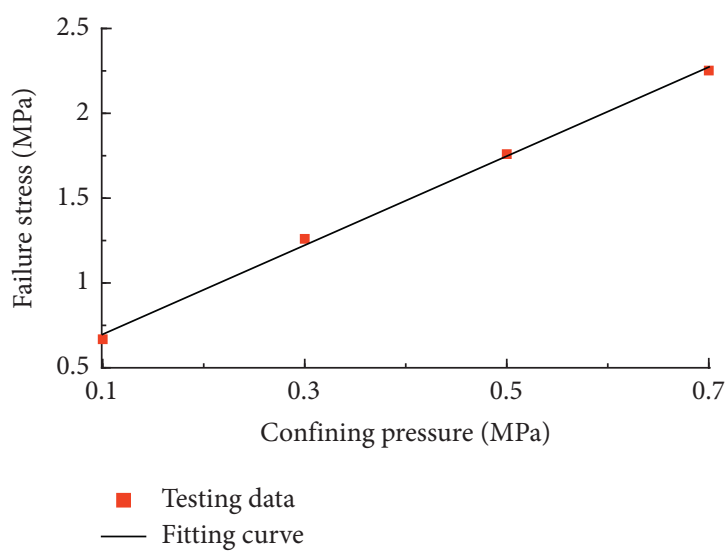

FIGURE 19: Failure stress of stabilized soils with different confining pressure (stabilizer content $=5 \%$; curing time $=3$ days).

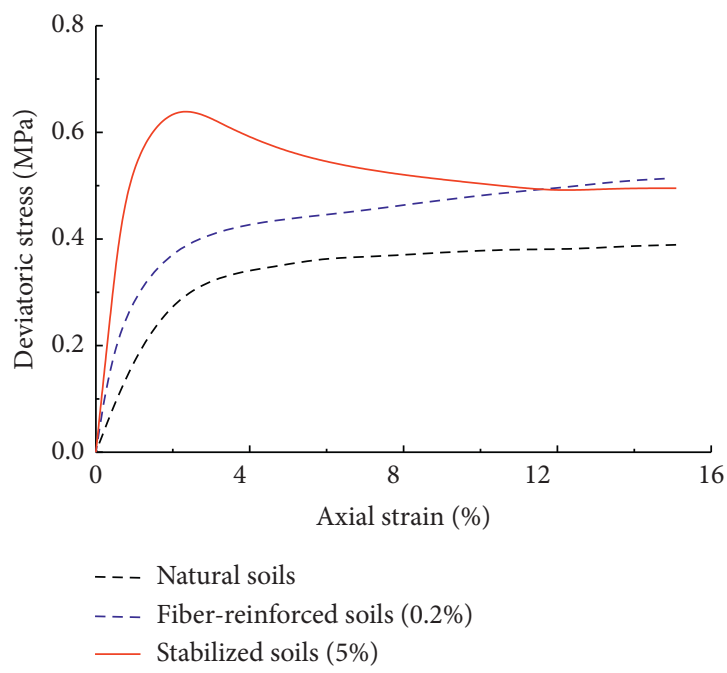

FIgURE 20: Deviatoric stress for different soils (confining pressure $=0.1 \mathrm{MPa}$ ). 
TABLE 5: Cohesion intercept and friction angle of soils.

\begin{tabular}{lcc}
\hline Soil type & $\begin{array}{c}\text { Cohesion intercept } \\
(\mathrm{MPa})\end{array}$ & $\begin{array}{c}\text { Friction angle } \\
\left({ }^{\circ}\right)\end{array}$ \\
\hline Natural soils & 0 & 38.0 \\
Fiber-reinforced soils & 0.11 & 37.7 \\
Stabilized soils & 0.11 & 34.7 \\
\hline
\end{tabular}

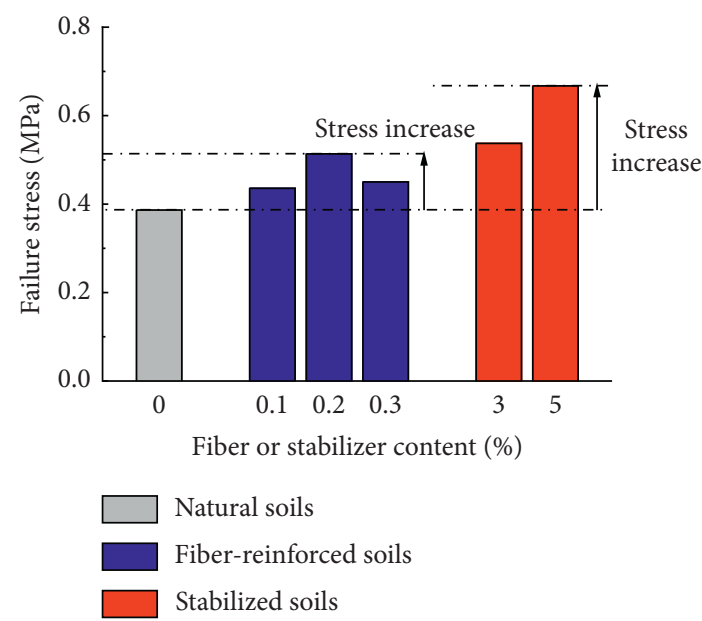

Figure 21: Failure stress for different soils (confining pressure $=0.1 \mathrm{MPa}$ ).

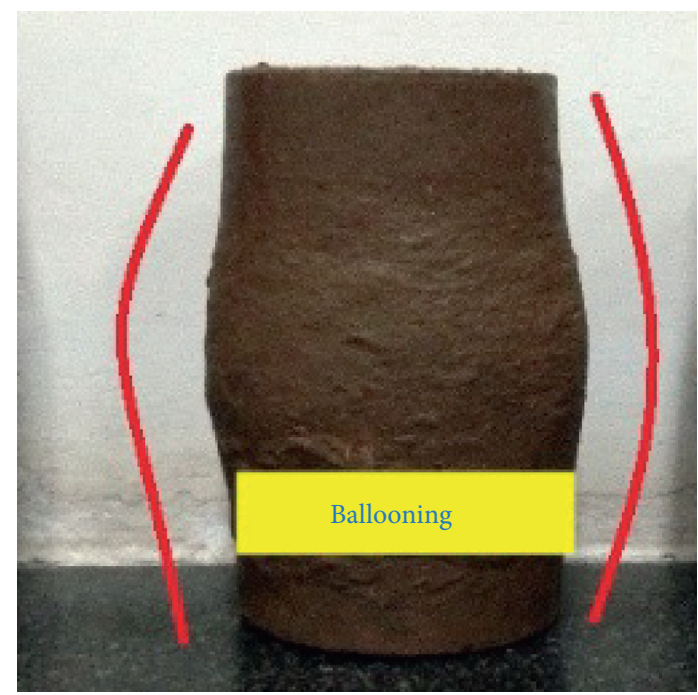

Figure 22: Appearances of natural soils after failure.

stabilizer content of $3 \%$ and $5 \%$, respectively. There is an increase in failure stress for both fiber-reinforced soils and stabilized soils. The failure stress for stabilized soils is higher than that for fiber-reinforced soils. Besides, with the change of fiber content and stabilizer content, soils showed different failure stress.

3.4.3. Appearances of Soils Specimens after Tests. Figures 22-24 show the appearances of soils after failure. As shown in Figure 22, natural soils generated ballooning

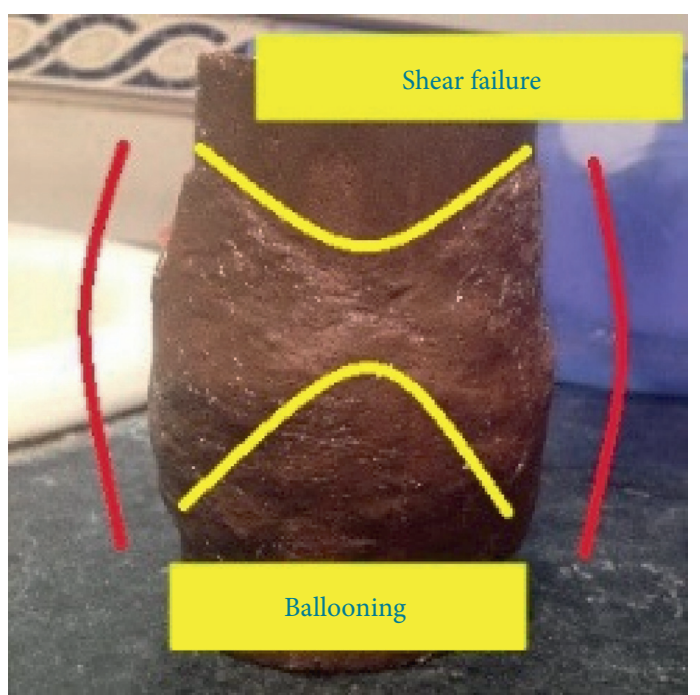

FIGURE 23: Appearances of fiber-reinforced soils after failure.
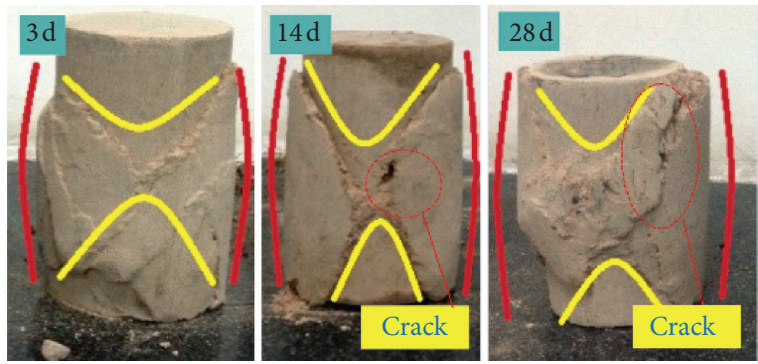

FIGURE 24: Appearances of stabilized soils after failure.

excessive damage with no crack. For fiber-reinforced soils, the specimens illustrated a deformation in shear failure and ballooning excessive damage, as shown in Figure 23. Figure 24 contains three different stabilized soils, cured for 3 days, 14 days, and 28 days, respectively. All the stabilized soils showed a brittle fracture and a deformation in shear failure. For stabilized soils cured for 3 days, the specimens showed ballooning excessive damage without crack. For stabilized soils cured over 14 days, a visible crack appeared after failure with more than one shear fracture plane. With an increase of curing time, the stabilizer had better chemical reactions with soil particles creating much more crystallization outcomes and consuming more water. The crystallization and matric suction result in the increase of soil strength and brittleness.

\section{Conclusions}

This study was undertaken to investigate the mechanical properties of natural soils in heavy-haul railway embankment, fiber-reinforced soils, and stabilized soils by performing conventional triaxial compression tests. The results of this study bring forth the following conclusions:

(1) The undrained stress-strain behavior of natural soils has a strain hardening character. Considerable increase of initial tangential modulus and failure stress 
was induced by the increase of compaction degree and confining pressure. The water content heavily influences the deviatoric response of the natural soils, and, with the optimum water content, $8.5 \%$, the soils performed better.

(2) The deviatoric stress-axial strain relationship for fiber-reinforced soils has no peak shear strength point, similar to natural soils. The improvement of initial tangential modulus and failure stress of fiberreinforced soil is limited with optimum content and length, $0.2 \%$ and $12 \mathrm{~mm}$, respectively. The failure stress for the fiber-reinforced soils grows linearly as confining pressure increases.

(3) Stabilized soils generated a peak deviatoric stress in the process of axial compression and the brittleness of soils increased if fiber contents increased. With the increasing of fiber contents, curing time, and confining pressure, the initial tangential modulus and failure stress for stabilized soils increased, which are superior to the fiber-reinforced soils. The residual shear strength increases with the increase of stabilizer content and confining pressure. However, it shows a decreasing character with the increasing of curing time.

(4) Shear strength increases as a result of fiber reinforcement and stabilizer reinforcement for the natural soils in heavy-haul railway embankment. The reinforced soils are efficient for heavy-haul railway embankment, which is close to the ground surface. In the process of determining the reinforcement methods, several other considerations are included, such as equipment and time available.

(5) It should be pointed out that these results are valid only for the natural soils utilized in this study. However, the results can also provide guidance or references to the other similar projects. In addition, the dynamic load and scale effect on the mechanical properties of the reinforced soils have not been investigated thoroughly. Hence, further studies including dynamic stabilities and large-scale tests are needed to better understand the characteristics of fiber-reinforced soils and stabilized soils.

\section{Data Availability}

Some data used during the study are available from the corresponding author upon request.

\section{Conflicts of Interest}

The authors declare no conflicts of interest.

\section{Acknowledgments}

This work was supported by the State Key Laboratory of Frozen Soil Engineering (SKLFSE201907), National Major Scientific Instruments Development Project of China (41627801), National Key R\&D Program of China
(2018YFC1505300), and Postgraduate Research and Practice Innovation Program of Jiangsu Province (KYCX19_0093).

\section{References}

[1] T. K. Rajak, L. Yadu, and S. K. Pal, Analysis of Slope Stability of Fly Ash Stabilized Soil Slope, Geotechnical Applications, Singapore, 2019.

[2] J. S. Horvath, "Using geosynthetics to reduce surcharge-induced stresses on rigid earth-retaining structures," Transportation Research Record, vol. 1330, 1991.

[3] K. Makiuchi and K. Minegishi, "Strain-induced toughness and shearing characteristics of short-fiber reinforced soils," in Proceedings of the International Symposium on Earth Reinforcement, pp. 83-88, Lisse, Netherlands, November 2001.

[4] T. Park and S. Tan, "Enhanced performance of reinforced soil walls by the inclusion of short fiber," Geotextiles and Geomembranes, vol. 23, no. 4, pp. 348-361, 2005.

[5] A. Arulrajah, A. Abdullah, M. W. Bo, and A. Bouazza, "Ground improvement techniques for railway embankments," Proceedings of the Institution of Civil Engineers Ground Improvement, vol. 162, no. 1, pp. 3-14, 2009.

[6] S. M. Hejazi, M. Sheikhzadeh, S. M. Abtahi, and A. Zadhoush, "A simple review of soil reinforcement by using natural and synthetic fibers," Construction and Building Materials, vol. 30, pp. 100-116, 2012.

[7] D. H. Gray and H. Ohashi, "Mechanics of fiber reinforcement in sand," Journal of Geotechnical Engineering, vol. 109, no. 3, pp. 335-353, 1983.

[8] T. Yetimoglu and O. Salbas, "A study on shear strength of sands reinforced with randomly distributed discrete fibers," Geotextiles and Geomembranes, vol. 21, no. 2, pp. 103-110, 2003.

[9] W. Shao, B. Cetin, Y. Li, J. Li, and L. Li, "Experimental investigation of mechanical properties of sands reinforced with discrete randomly distributed fiber," Geotechnical and Geological Engineering, vol. 32, no. 4, pp. 901-910, 2014.

[10] D. H. Gray and T. Al-Refeai, "Behavior of fabric-versus fiberreinforced sand," Journal of Geotechnical Engineering, vol. 112, no. 8, pp. 804-820, 1986.

[11] N. C. Consoli, M. A. Vendruscolo, A. Fonini, and F. D. Rosa, "Fiber reinforcement effects on sand considering a wide cementation range," Geotextiles and Geomembranes, vol. 27, no. 3, pp. 196-203, 2009.

[12] A. P. S. Dos Santos, N. C. Consoli, and B. A. Baudet, "The mechanics of fibre-reinforced sand," Géotechnique, vol. 60, no. 10, pp. 791-799, 2010.

[13] Z. W. Gao and J. D. Zhao, "Evaluation on failure of fiberreinforced sand," Journal of Geotechnical and Geoenvironmental Engineering, vol. 139, no. 1, pp. 95-106, 2012.

[14] R. L. Santoni, J. S. Tingle, and S. L. Webster, "Engineering properties of sand-fiber mixtures for road construction," Journal of Geotechnical and Geoenvironmental Engineering, vol. 127, no. 3, pp. 258-268, 2001.

[15] J. S. Tingle, R. L. Santoni, and S. L. Webster, "Full-scale field tests of discrete fiber-reinforced sand," Journal of Transportation Engineering, vol. 128, no. 1, pp. 9-16, 2002.

[16] A. A. Al-Rawas and M. F. Goosen, Expansive Soils: Recent Advances in Characterization and Treatment, Taylor \& Francis, Oxfordshire, England, UK, 2006.

[17] J. Prabakar, N. Dendorkar, and R. K. Morchhale, "Influence of fly ash on strength behavior of typical soils," Construction and Building Materials, vol. 18, no. 4, pp. 263-267, 2004. 
[18] A. A. Al-Rawas, A. W. Hago, and H. Al-Sarmi, "Effect of lime, cement and sarooj (artificial pozzolan) on the swelling potential of an expansive soil from Oman," Building and Environment, vol. 40, no. 5, pp. 681-687, 2005.

[19] R. K. Goswami and B. Singh, "Influence of fly ash and lime on plasticity characteristics of residual lateritic soil," Proceedings of the Institution of Civil Engineers - Ground Improvement, vol. 9, no. 4, pp. 175-182, 2005.

[20] R. L. Parsons and E. Kneebone, "Field performance of fly ash stabilised subgrades," Proceedings of the Institution of Civil Engineers - Ground Improvement, vol. 9, no. 1, pp. 33-38, 2005.

[21] K. M. A. Hossain, M. Lachemi, and S. Easa, "Stabilized soils for construction applications incorporating natural resources of papua new guinea," Resources, Conservation and Recycling, vol. 51, no. 4, pp. 711-731, 2007.

[22] M. A. Mu'Azu, "Influence of compactive effort on bagasse ash with cement treated lateritic soil," Leonardo Electronic Journal of Practices and Technologies, vol. 6, no. 10, pp. 79-92, 2007.

[23] M. G. Bisanal and R. Badiger, "Study on stabilization of soil using sea shell and bitumen emulsion," International Journal of Innovative Research in Science, Engineering and Technology, vol. 4, no. 7, 2015.

[24] A. Maher, T. Bennert, F. Jafari, W. S. Douglas, and N. Gucunski, "Geotechnical properties of stabilized dredged material from New York-New Jersey harbor," Transportation Research Record, vol. 1874, no. 1, pp. 86-96, 2004.

[25] T. Zhang, G. J. Cai, and S. Y. Liu, "Reclaimed lignin-stabilized silty soil: undrained shear strength, atterberg limits, and microstructure characteristics," Journal of Materials in Civil Engineering, vol. 30, no. 11, 2018.

[26] A. Diambra, E. Ibraim, D. Muir Wood, and A. R. Russell, "Fibre reinforced sands: experiments and modelling," Geotextiles and Geomembranes, vol. 28, no. 3, pp. 238-250, 2010.

[27] K. S. Heineck, M. R. Coop, and N. C. Consoli, "Effect of microreinforcement of soils from very small to large shear strains," Journal of Geotechnical and Geoenvironmental Engineering, vol. 131, no. 8, pp. 1024-1033, 2005. 